\title{
Youth participation in civil society and political life in India
}

International Institute for Population Sciences (IIPS)

Population Council

Follow this and additional works at: https://knowledgecommons.popcouncil.org/departments_sbsr-pgy

Part of the Civic and Community Engagement Commons, Demography, Population, and Ecology Commons, Family, Life Course, and Society Commons, International Public Health Commons, and the Social Policy Commons How does access to this work benefit you? Let us know!

\section{Recommended Citation}

International Institute for Population Sciences (IIPS) and Population Council. 2010. "Youth participation in civil society and political life in India," Youth in India: Situation and Needs Policy Brief no. 30. Mumbai: IIPS. 


\section{Youth participation in civil society and political life in India}

Youth participation in civil society and political life is increasingly recognised as an important development objective. The opportunities for participation that young people experience in their communities may influence their development and the kind of transitions they make to adulthood. For example, evidence that comes largely from developed countries indicates that youth who participate in community activities or are connected to their communities are less likely than others to engage in risk-taking behaviours. Moreover, behaviours and attitudes relating to community participation that individuals adopt as young people predict their lifelong civic affiliations and perspectives. ${ }^{a}$

In India, the National Youth Policy 2003 has underscored the role of India's youth in political decision-making, and has argued for greater representation of youth in appropriate bodies as well as more extensive youth participation in the design and implementation of programmes. ${ }^{b}$ Indeed, there is a recognition that today's youth, who have better access to skills and information than those of earlier generations, can play an important role in influencing political processes and the socio-economic development of the country. However, there is very little evidence of the extent to which Indian youth participate in civil society and political life.

This policy brief documents the participation of youth in India in civil society, the extent to which they uphold secular attitudes and their perceptions about and participation in political processes.

\section{The study}

Data are drawn from the Youth in India: Situation and Needs study, a sub-nationally representative study undertaken for the first time in India of key transitions experienced by young people in six states of India, namely, Andhra Pradesh, Bihar, Jharkhand, Maharashtra, Rajasthan and Tamil Nadu. These states were purposively selected to represent the different geographic and socio-cultural regions within the country, and these six states together represent two-fifths of the country's population. The study included a representative survey of young people in both rural and urban settings. Respondents included unmarried women and men and married women aged 15-24 and, in view of the paucity of married men in these ages, married men aged 15-29.

The survey was conducted in a phased manner in the six states, between January 2006 and April 2008. A total of 50,848 married and unmarried young men and women were interviewed in the survey. These included 8,052 married young men, 11,522 unmarried young men, 13,912 married young women and 17,362 unmarried young women. This brief is based on data obtained from 14,281 young men and 31,274 young women aged 15-24.

To what extent do young people participate in civil society?

Participation in civil society, as measured by participation in community-led activities or membership in an organised group, was limited among youth, particularly among young women. Specifically, $45 \%$ of young men compared to only $15 \%$ of young women reported that they had participated in any community-led programmes such as cleanliness drives, health promotion activities, and celebration of festivals and national days. Far fewer young men (11\%) and women (10\%) reported membership in organised groups such as self-help groups, and sports and social clubs. In total, $48 \%$ of young men and $23 \%$ of young women reported participation in civil society.

Findings indicate that participation in civil society was more likely to be reported by better than less educated youth, and differences were particularly wide among young men. For example, $34 \%$ of young men with less than 9 years of schooling had participated in civil society, compared to $57 \%$ of those with at least 9 years of schooling. The corresponding percentages among young women were 17 and 31 .

\footnotetext{
a National Research Council and Institute of Medicine. 2005. Growing up Global: The Changing Transitions to Adulthood in Developing Countries. Washington, D.C.: The National Academies Press.

b Ministry of Youth Affairs and Sports. 2003. National Youth Policy 2003. New Delhi: Ministry of Youth Affairs and Sports, Government of India.
} 
Findings also show that more unmarried than married youth reported participation in civil society. Half $(51 \%)$ of unmarried young men compared to one-third (34\%) of married young men reported such participation. Among young women, differences were much narrower: $27 \%$ of the unmarried compared to $20 \%$ of the married had participated in civil society. Rural-urban differences were narrow among both young men and women.

State-wise differentials in participation in civil society were marked, with considerably more youth in Maharashtra and the southern states of Andhra Pradesh and Tamil Nadu reporting such participation than those in the northern states of Bihar, Jharkhand and Rajasthan. Indeed, while just $24-35 \%$ of young men and $5-15 \%$ of young women from the northern states had participated in civil society, a much larger proportion$56-66 \%$ of young men and $25-39 \%$ of young women - of those from Maharashtra and the southern states had done so.

Do young people uphold secular attitudes? In order to gauge the extent to which youth uphold secular attitudes, two issues were addressed. The first assessed young people's attitude to social interaction with individuals of different castes and religions. Specifically, youth were asked whether they would mix freely and eat together with a person from a different caste or religion, and would talk to someone who had an inter-caste marriage. The second issue assessed young people's tolerance towards someone who showed disrespect to their religion. Specifically, youth were asked whether or not they considered it acceptable to punish someone who showed disrespect to their religion.

Findings show that the overwhelming majority of young men and women (89-96\%) expressed secular attitudes about mixing freely with individuals of different castes and religions. However, considerably fewer reported that they would eat together with a person of another caste or religion or talk to someone who had an inter-caste marriage: $82 \%$ and $71 \%$, respectively, of young men, and $67 \%$ and $68 \%$, respectively, of young women.

Only $63 \%$ of young men and $51 \%$ of young women reported affirmatively to all four items. Better educated youth were far more likely than their less educated counterparts to report affirmatively to all four items and the differences were more pronounced among young women than among young men: $69 \%$ compared to $53 \%$ among young men and $68 \%$ compared to $37 \%$ among young women. Secular attitudes in all four situations were more likely to be reported by unmarried young men and women than by their married counterparts (66\% compared to $51 \%$ among young men and $57 \%$ compared to $45 \%$ among young women). Likewise, secular attitudes in all four situations were more likely to be reported by urban youth (77\% of young men and $68 \%$ of young women) compared to rural youth (57\% of young men and $43 \%$ of young women).

State-wise differentials in reporting of secular attitudes in all four situations were again marked and regional patterns appear clearly. While just $23-35 \%$ of young men and $12-14 \%$ of young women from the northern states reported secular attitudes in all four situations, a much larger proportion-85-91\% of young men and 66-85\% of young women from Maharashtra and the southern states reported so.

In addition, fewer than one-third of young men (29\%) and just two-fifths of young women (39\%) considered it unacceptable to retaliate,

Percentage of youth who participated in civil society, according to selected characteristics and state

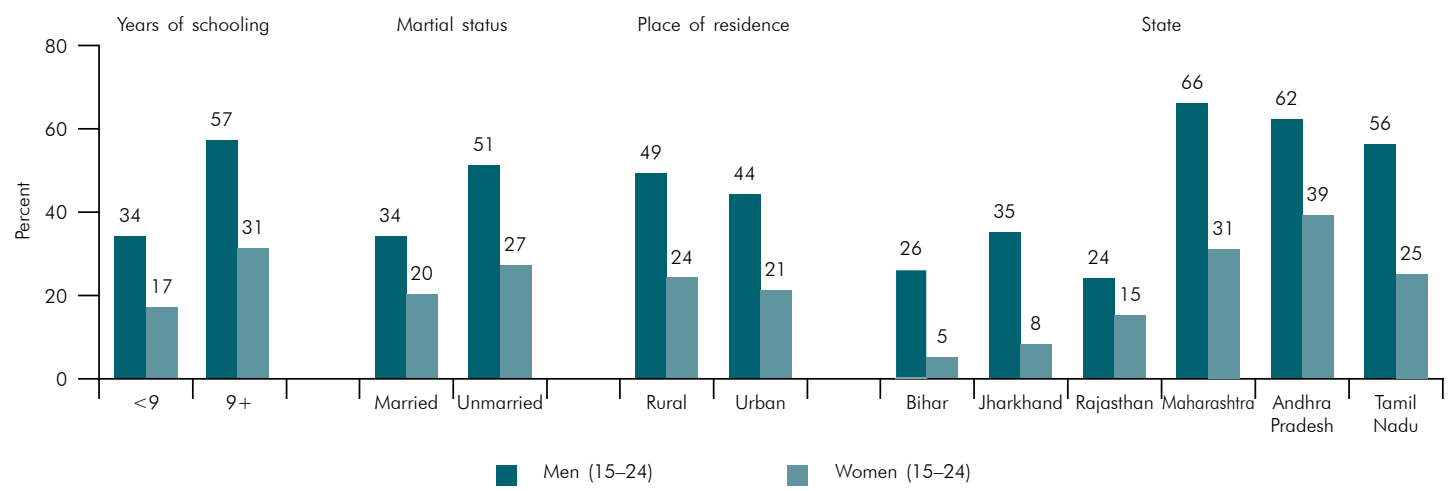


POLICY BRIEF Youth participation in civil society and political life in India

Percentage of youth expressing secular attitudes

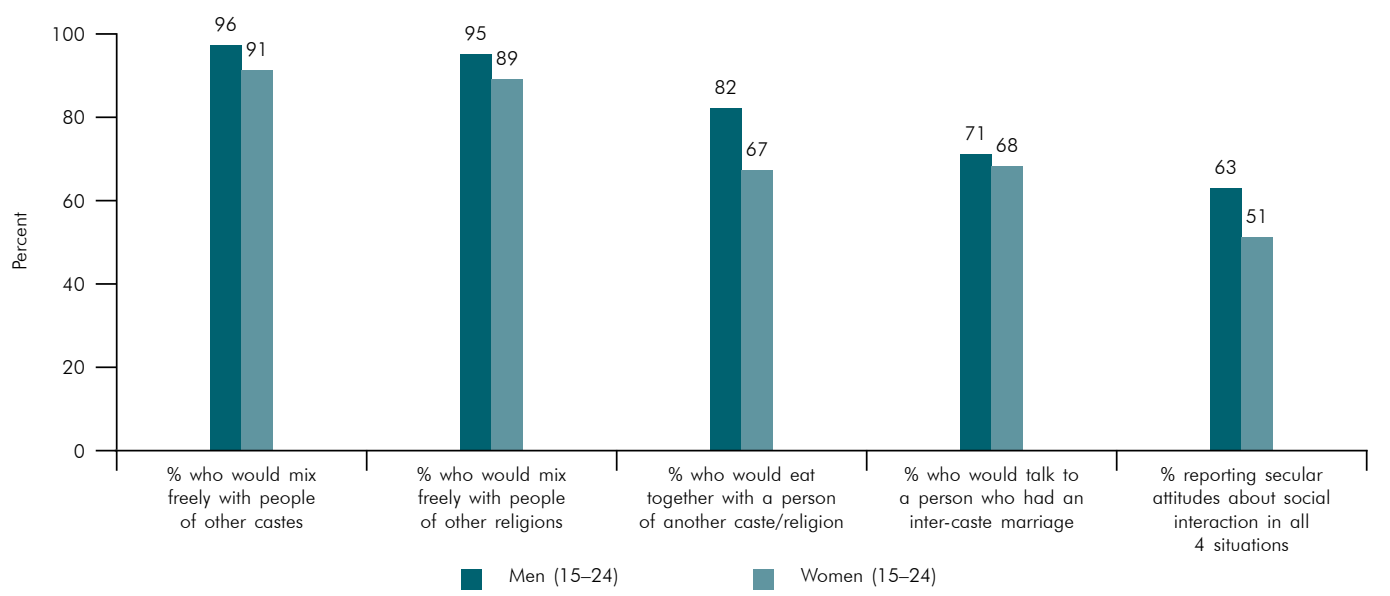

through punitive action, against someone who showed disrespect to their religion.

What do young people think about the commitment of political parties and fairness of the electoral process?

Considerable proportions of youth reported disillusionment with the commitment of political parties to work for change at the community level. Indeed, $68 \%$ of young men and $57 \%$ of young women believed that improvement in their village (rural youth) or neighbourhood (urban youth) was unlikely, no matter which political party governed the state.

It is notable, however, that the majority of youth - $83-86 \%$ - perceived that the electoral process was fair and one could vote without fear or pressure. Even so, slightly less than one-sixth (14-17\%) were unsure or felt that one could not vote freely.
Do young people exercise their voting rights? Findings suggest that of those who were eligible to vote in the last election preceding the interview (aged 20 years and above at the time of the interview), seven out of ten young men $(71 \%)$ and three-fifths of women $(60 \%)$ had cast their vote. Differentials in voting by years of schooling completed were modest. Marital status differences suggest that the married were more likely than the unmarried to have voted in the last election: $77 \%$ and $67 \%$ among married and unmarried young men, respectively; and $62 \%$ and $51 \%$, respectively, among young women. Likewise, rural youth $(74 \%$ of men and $63 \%$ of women) were more likely than urban youth ( $64 \%$ of men and $52 \%$ of women) to have voted in the last election.

State-wise differentials were apparent, but the consistent regional pattern observed earlier was not observed. Among young men, considerably

Percentage of youth expressing secular attitudes, according to selected characteristics and state

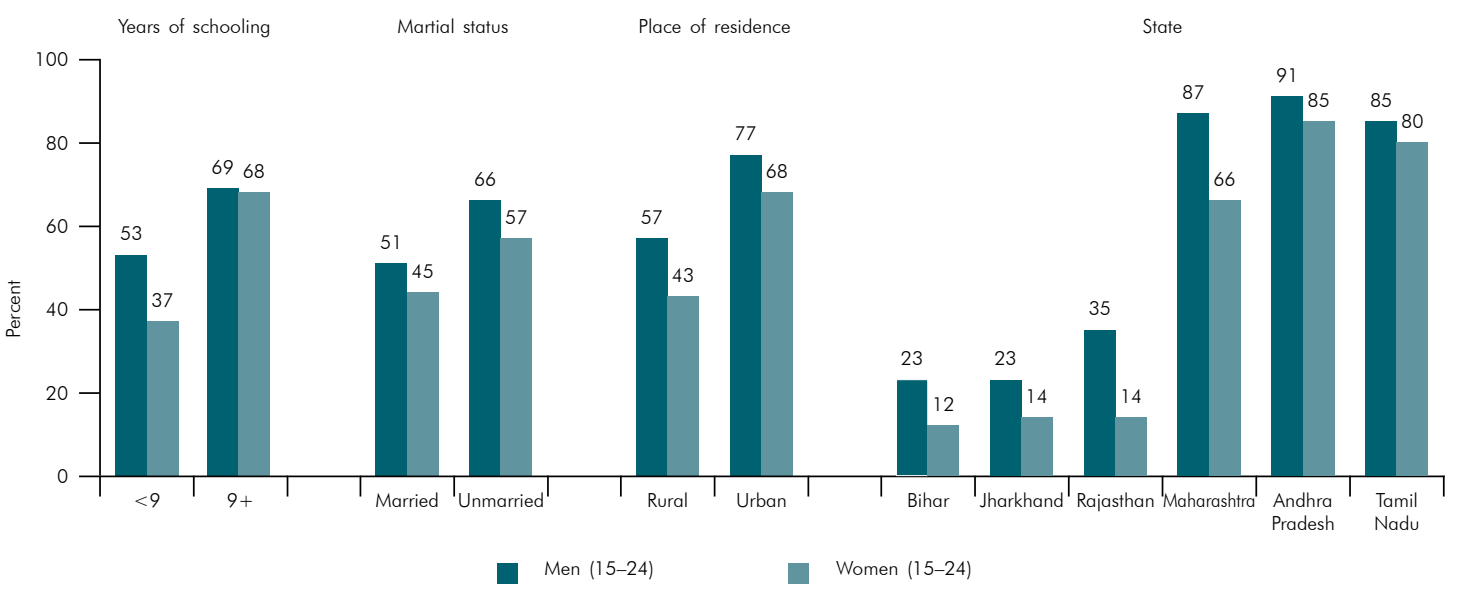


Percentage of youth aged 20 and above who had voted in the last election preceding the interview, according to selected characteristics

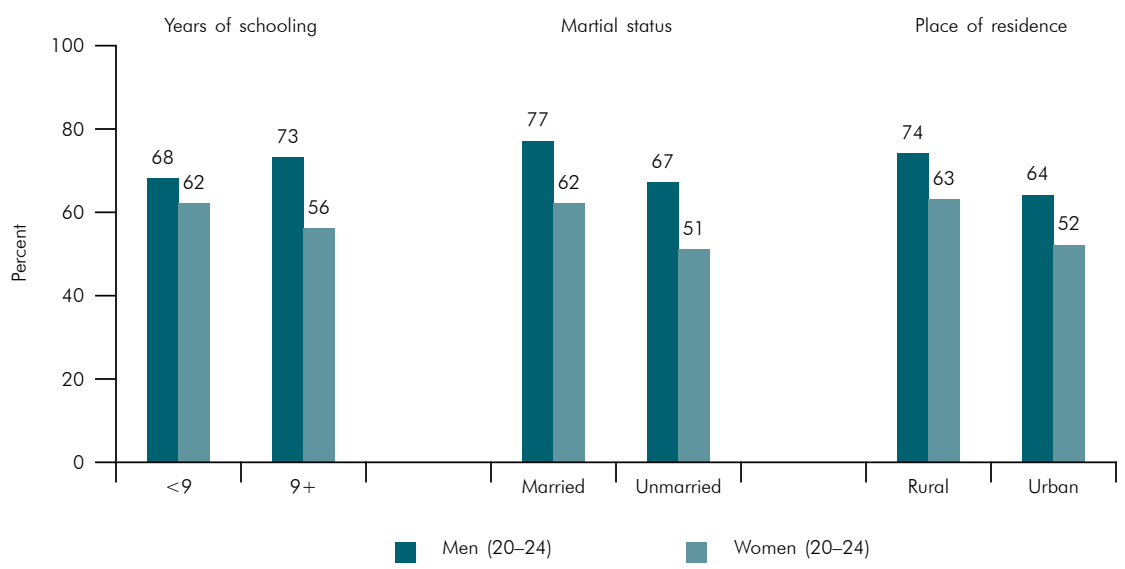

Percentage of youth aged 20 and above who had voted in the last election

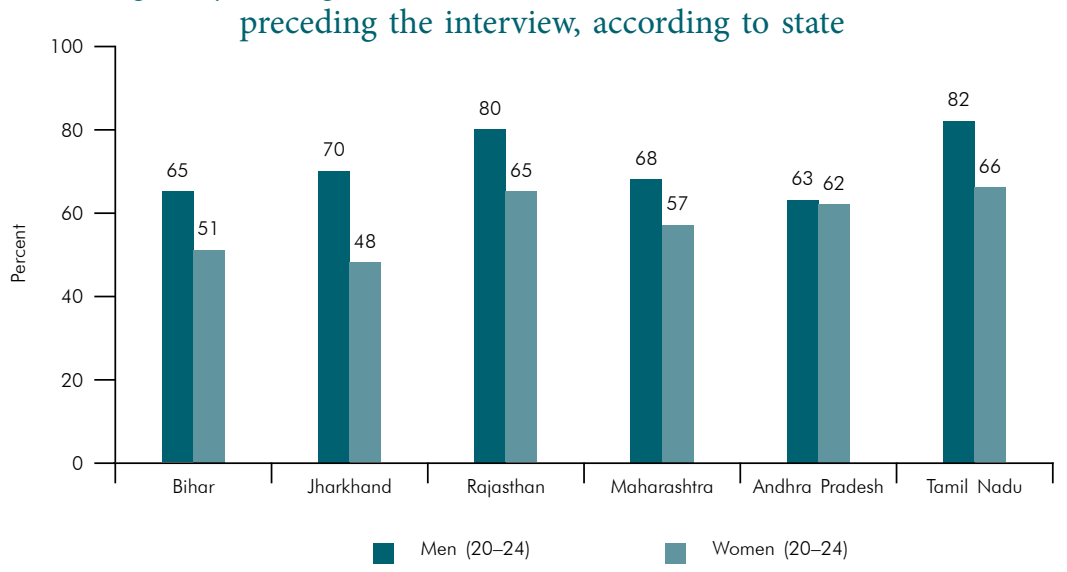

larger proportions of those from Rajasthan and Tamil Nadu than those in the remaining four states had voted in the last election $(80-82 \%$ versus $63-70 \%)$. Among young women, in contrast, more of those from Rajasthan, Tamil Nadu as well as Andhra Pradesh voted than did those in the remaining three states (62-66\% versus $48-57 \%)$.

\section{Programme recommendations}

Findings call for actions to promote youth participation, particularly the participation of young women, in civil society and political life. Programmes are needed at the school, college and community levels-through national service programmes, sports and other non-formal mechanisms-that encourage civic participation, incorporate value building components and reinforce secular attitudes and values that espouse responsible citizenship. Findings indicating that youth participation in civil society and the expression of secular attitudes were far more limited in the northern states than in Maharashtra and the southern states emphasise that these programmes in these northern states must make special efforts to involve youth.

Findings that many youth are disillusioned with the commitment of political parties to work for change at the community level highlight the need for the political system in every state to make special efforts to address the concerns of youth and encourage youth participation in the political processes in more meaningful ways. 